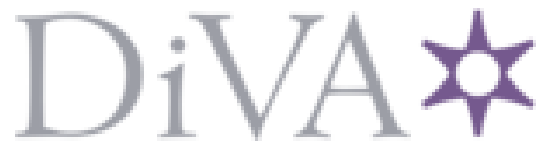

http://www.diva-portal.org

Preprint

This is the submitted version of a paper presented at IEEE Conference on Technologies for Sustainability (SusTech 2017).

Citation for the original published paper:

Gürdür, D., Tasala Gradin, K. (2017)

Interoperable Toolchains in Cyber-physical Systems with a Sustainability Perspective.

In: IEEE Conference on Technologies for Sustainability Proceedings Phoenix, AZ,

USA: Institute of Electrical and Electronics Engineers (IEEE)

N.B. When citing this work, cite the original published paper.

(C)2017 IEEE

Permanent link to this version:

http://urn.kb.se/resolve?urn=urn:nbn:se:kth:diva-217836 


\title{
Interoperable Toolchains in Cyber-physical Systems with a Sustainability Perspective
}

\author{
Didem Gürdür*, Katja Tasala Gradin \\ Department of Machine Design, \\ KTH Royal Institute of Technology, \\ Stockholm, Sweden \\ \{dgurdur, katjag\}@kth.se
}

\begin{abstract}
The development of cyber-physical systems (CPS) requires various engineering disciplines, artifacts, and areas of expertise to collaborate. Powerful software tools are used during this development process, but while successful in one individual discipline, it is often challenging to integrate with other tools. Several studies have been done on integration solutions for these toolchains. However, the possibility of including the sustainability concept to the interoperability strategies is rarely studied. This paper discusses an approach to include sustainability aspects while improving the interoperability of toolchains in CPS manufacturing. To this end, an automobile manufacturing process has been studied as a use case, and relevant sustainability metrics for each stage of the process are identified. Life cycle sustainability assessment methodology is used to identify the sustainability metrics, and the use case is employed to exemplify how some of these metrics can be integrated with interoperable toolchains to illustrate the applicability of the approach.
\end{abstract}

Keywords—toolchain interoperability; tool integration; interoperability; sustainability; life cycle sustainability assessment

\section{INTRODUCTION}

Cyber-physical systems are systems that include integration of computation, networking, and physical processes with feedback loops where physical processes affect computations and vice versa [1]. These systems are a result of product development processes, which include multidimensional complexity. In CPS manufacturing, these processes are tightly integrated. Throughout this paper, we have grouped these processes as product life cycle stages. These product life cycle stages include different engineering disciplines, development and production departments, and software tools working together.

This becomes problematic since many of the software tools employed throughout the different processes typically come from separate sources and are hence likely to be incompatible. For seamlessly integrated toolchains, these software tools should be able "to exchange and use information" [2]. In other words, they should be interoperable. Yet today, no completely interoperable toolchains exist that support continuous design and development of CPS throughout the product life cycle stages. Nevertheless, the need for continuous manufacturing is a fundamental requirement for the growth of competitive small and large companies [3], and to consistently improve productivity and efficiency; this is directly proportional to the

* Corresponding author. performance of interoperable toolchains.

Another important concept, and perhaps the least studied, to consider during CPS manufacturing is sustainability. Sustainability has three main pillars that feature economic, social, and environmental issues. Even though these aspects are independent, they are not mutually exclusive but mutually reinforcing [4]. This research is based on the hypothesis that toolchain interoperability solutions offer an opportunity to include sustainability assessment metrics from all three pillars of sustainability; hence, we can improve the sustainability of CPS through well-constructed interoperable toolchains, which have the sustainability perspective.

This paper does not necessarily focus on the technical discussion about the interoperability or integration solutions. Rather, we aim to draw the attention of developers of these integration solutions to include sustainability metrics into their technologies. To this end, this paper investigates the applicability of integrating sustainability assessment throughout interoperable toolchains. The purpose of this research is, therefore, to answer the research questions (RQs) below:

$R Q$ 1: What are the important sustainability metrics from all three dimensions that are important to consider during the product life cycle stages?

$R Q$ 2: How can these metrics be extracted from software tools and used through interoperable toolchains for the purpose of assessing sustainability?

This paper exemplifies how this can be done using a sample case study. An example of automobile manufacturing is illustrated by explaining the product life cycle stages and information flow of sustainability metrics between different tools.

This paper is organized into five sections: Section II presents the details of background studies. Section III summarizes the methodology taken during the assessment of the case study, and Section IV describes the case study in detail. The discussion on the approach is presented in Section $\mathrm{V}$, where the research questions are answered. Finally, the paper concludes with a summary of the study in Section VI.

\section{BACKGROUND}

In this paper, two main concepts (interoperability and sustainability) will be discussed with focus on unifying them. For this reason, this section aims to give a summary of the background of these two concepts. 


\section{A. Sustainability}

One view on sustainability is grounded in the concept of sustainable development summarized in the 1987 report of the Brundtland Commission as "meeting the needs of the present without compromising the ability of future generations to meet their own needs" [4]. Later, hundreds of definitions proposed referring to a more humane, more ethical, more transparent way of doing business that matches the development, awareness, and ambition levels of organizations [5].

Undoubtedly, the industry needs more sustainable strategies. Thus, the importance of sustainability has been supported by a number of organizations, including scholars, practitioners, public bodies, governmental and nongovernmental agencies, and consulting firms.

One example related with CPS is the concept of Industry 4.0 [6]. This concept can be briefly described as the fourth stage of industrialization. This stage follows the third industrial revolution, which started in the early 1970s and was based on electronics and information technologies for realizing a high level of automation in manufacturing [7]. Currently, Industry 4.0 mainly focuses on the environmental dimension of sustainability. This dimension primarily concerns the allocation of resources, such as products, materials, energy, and water. However, it also presents a great opportunity on all three sustainability dimensions [8].

Stock and Seliger [8] discuss these opportunities in detail with highlighting macro and micro perspectives of Industry 4.0. In the macro perspective, two main opportunities are mentioned as business models and value creation networks. Besides contributing to the solutions of environmental or social problems [9], sustainable business models are seen as a promising direction to create positive impacts or reduce negative impacts on the environment and society [10]. Value creation networks are discussed as an opportunity for realizing closed-loop product life cycles and industrial symbiosis.

Furthermore, equipment, human, organization, process, and product dimensions are considered opportunities in the micro perspective. The manufacturing equipment contributes to the economic and environmental dimensions of sustainability through a long use phase where humans are seen as organizers of value creation in Industry 4.0. Opportunities related to the organization focus on the efficient distribution of products, materials, energy, and water. The sustainable design of processes addresses the holistic resource efficiency approach of Industry 4.0 by designing appropriate manufacturing process chains [11], and sustainable product design is mentioned in relation to the closed-loop life cycles for products.

In this paper, we will focus on the micro perspective of sustainability and discuss how we can include the sustainability concept and related metrics through toolchains.

\section{B. Interoperability}

The interoperability definition we use in this paper has a similar boundary as the sustainability definition. The focus, in this paper, is limited by the interoperability between software tools used for CPS manufacturing. The most relevant definition of interoperability, which we mention in this paper, is found from industrial automation systems and integration standards, ISO 16100-1:2009 [12]. In ISO 16100-1:2009, manufacturing software interoperability is defined as "the ability to share and exchange information using common syntax and semantics to meet an application-specific functional relationship."

During the literature review for this paper, we found no research concerning the relationship of sustainability and tool interoperability within the CPS context. However, some papers have been identified as relevant to be mentioned.

Penzenstadler et al. [13] published a systematic literature review that provides an overview of different aspects of sustainability in software engineering research. The authors identified four aspects of sustainability in software engineering: development process, maintenance process, system production, and system usage. While these aspects heavily cover the life cycle of the software, there is no specific attention on the interoperability of the software tools.

Dassisti et al. [14], for instance, applied the dualistic sustainability and interoperability viewpoint to a variety of areas, including manufacturing. The authors emphasized virtual manufacturing as a new paradigm that has the potential to improve the capability of sharing and managing knowledge and synchronizing cooperation activities in a form that is useful to human decisions. Moreover, the study introduced virtual sustainability in a similar way, with the authors commenting that "provided adequate tools are available, one can assess the sustainability of processes or products before any concrete action is taken, in a conceptual stage and independently of the manufacturing chain stage. It is only a matter of the quality and power of modeling and simulation tools, techniques and applications to offer new opportunities to evaluate the impact on resource consumption and environment because of these features."

Agostinho et al. [15] studied the challenges of sustaining networked enterprise information systems. In this paper, sustainable interoperability is defined as "the interoperability that convenes the needs of the present without compromising the ability of future changes, meeting new system requirements, and performing adequate adaptation and suitable management of the transitory elements." Different than our focus, Agostinho et al.'s definition of sustainability focuses on the quality and efficiency of interoperability, which delineates the capacity to endure and improve cooperation between different enterprises. Furthermore, Jardim-Goncalves et al. [16] also took an approach similar to Agostinho et al. by focusing on strategies, methods, and tools to maintain and sustain the interoperability of enterprise systems in networked environments.

\section{METHODOLOGY}

In this study, we adopted life cycle sustainability assessment (LCSA) as a methodology to assess the level of sustainability of CPS. Traditionally, the life cycle of a product, service, or process involves inputs and outputs in the form of material resources, energy, money, etc. A full life cycle includes raw material extraction, manufacturing, use, and end of life phases [17]. However, the assessment is not complete without assessing manufacturing, use, and impacts on actors along the value chain -workers, local communities consumers, and society [18]. LCSA aims to assess sustainability with respect to the triple bottom line of environment, economy, and social impacts [18]. Next, these three dimensions are 
summarized, and the associated sustainability assessment tools are presented.

\section{A. Environmental Dimension}

Life cycle assessment (LCA) is an established tool for evaluating the potential environmental impact during the life cycle, from cradle to grave, of a product, service, or process [19]. According to ISO 14040:2006 [17], the methodology involves an iterative process with four steps: defining the goals and scope of the LCA, performing inventory analysis, calculating is performed, impact assessments, and interpreting the results.

There are several software applications that support environmental considerations during vehicle design. A literature review by Poulikidou [20] identified several software and computer-based tools for design for the environment or eco design. Most software tools are used to simplify the LCA process by providing ready - made databases, structuring the input data, and performing all necessary calculations during the inventory and impact assessment processes [20].

\section{B. Economic Dimension}

Cost and performance are relevant for the economic dimension of sustainability and are calculated through several approaches. One approach is life cycle cost analysis (LCCA). According to Woodhouse [21], LCCA can be defined as a systematic process of technical-economical evaluation that considers, in a simultaneous way, economic and reliability aspects of an asset, quantifying the real impact on its life cycle cost. LCCA considers all costs arising during the life cycle of the product, process, or service [22]. Additionally, the product development stages should also be included. This requires a structuring of the costs associated with life cycle phases and a focus on money flows (in analogy to material and energy flows in LCA).

\section{Social Dimension}

The social life cycle assessment (S-LCA) is a tool that can be used to assess the social and sociological aspects of products, services, or processes, and their actual and potentially positive or negative impacts during the life cycle. S-LCA makes use of generic and site-specific data-which can be quantitative, semi-quantitative, or qualitative-and complements the environmental LCA and LCC. It can either be applied on its own or in combination with the other tools [23]. The Global Reporting Initiative [24] stated that the social benefits can be estimated by analyzing the effects of the organization on stakeholders at the local, national, and global levels.

The system boundary in this case study is set around the manufacturing of a vehicle, including the stages of conceive, design, realize, and service. It is not the main point of this paper to be all-inclusive, but rather to give an example of relationships between parts, including different departments, tools, and stakeholders. The main point is to show the applicability of including sustainability metrics while one develops an interoperable toolchain, and to start developing a conceptual framework around this concept.

\section{USE CASE}

In this use case, we selected to exemplify our approach with an automotive manufacturing life cycle phase. Since it is very difficult, complicated, and time-consuming to include the complete life cycle, enterprise parties/stakeholders, and design and development tools in detail in one study, we simplified the use case. Arguably, this case does not illustrate a full-scale product life cycle-which it does not intend to be-and one can probably find room for improvements. However, the main goal of this use case is to show the applicability of the concept and to explain how sustainability aspects could be integrated with interoperable toolchains throughout the product life cycle stages. To this end, we have divided the product life cycle into four stages: conceive, design, realize, and service.

The primary reason behind choosing an automobile as a CPS product is the diverse and influential nature of the automotive industry. Authors in [25] described the automotive industry as "the largest single manufacturing sector worldwide, the management practices, organizational forms, and particularly the response to environmental pressures adopted by this industry are important in their own right, but also in terms of influencing many other business sectors. The products of this industry touch our daily lives not only by providing personal mobility for millions but also by bringing a wide array of challenges. The deterioration of local air quality in urban areas, along with global issues such as global warming, and the treatment of scrapped vehicles are just a few examples of such challenges."

Another reason is the increasing embedded systems that exist in modern cars. Today, automobiles have different embedded systems, such as comforts and convenience systems (media players, voice recognition, mobile phone interfaces, audio systems, multimedia systems, digital radio); driver assistance systems (GPS, night vision, lane warning, adaptive cruise control, collision warning, tire pressure monitoring); information and communication systems (telematics, internet access) and data support for traffic congestions, service areas, parking areas, and road works. This integration of different embedded systems and the technological advances in automobiles make them a good example of CPS.

This study includes four stages of product life cycleconceive, design, realize, and service - in relation to the responsible departments, tool sets, and stakeholders. This structure accomodates enough complexity to show the importance of interactions and how each tool or toolset works together during the development and production of the end product. In this section, we will explain each stage and tools in detail by underlining the responsibility of each stakeholder. Furthermore, here, we exemplify the information flow from one tool to another one, which concerns the sustainability metrics.

\section{A. Stage 1:Conceive}

The conceive stage is the beginning of the project. In this stage, the idea for the project is explored and elaborated. The goals in the conceive stage are to examine the feasibility of the project, to define stakeholders to carry out the project, to specify the requirements associated with the product, to identify the expectations from the stakeholders with regard to the project result, etc. This stage comprises preconditions, 
functional requirements, operational requirements, and design limitations [26]. In our scenario, only the management department is included in this first stage since the main responsibilities are concerning project management and requirements management.

During this stage, the project manager specifies different milestones of the project, adds objectives/goals, and schedules the steps that need to be taken during the project. For all of these, sets of project management tools are needed. Moreover, these tools need to be integrated with other tools so that the project manager can be notified and informed throughout the manufacturing. We will list some sustainability metrics, which can be used to integrate project management tools in the conceiving stage with other relevant tools in different stages. For instance, the workload of each employee, projected time for each task, or health and safety situation are metrics that can be used to access the social dimension of sustainability; material cost, wages, or energy cost for economic sustainability; and environmental impact of material choice, level of energy consumption, or resource transport for the environmental dimension of sustainability.

The requirements manager defines the preconditions from the context within which the project must be conducted. For instance, working conditions are one of these preconditions. This aspect has a direct relationship with the social and economic dimensions of sustainability since the working conditions affect workers and the performance of workers also affect the cost. Functional requirements define specific behaviors or functions for the vehicle, such as technical details of the car, data processing, and manipulations or functionalities that systems need in an automobile management system. These functional requirements are also related to sustainability. For instance, technical details of the car directly affect the material selection and usage, which have major importance for the environmental and social sustainability dimension. The project manager allocates the resources to fulfill planned requirements as a next step. The project management tools support project managers by giving an overview of the project throughout initiation, planning, design, execution, monitoring, controlling, and closure of a project. Therefore, the project management tools have the potential to be integrated with other tools with sustainability metrics in focus. For instance, each requirement that has been defined can now have a relationship with project milestones. In addition, time spent to fulfill each requirement can be integrated with the project management tool. Moreover, the cost of this requirement can be updated throughout the project to assess economic sustainability.

\section{B. Stage 2: Design}

The second stage consists of design, modeling, simulation, and testing activities. In the design stage, several designs for different components are developed by different departments with different goals, which are connected to the requirements. Since the design stage is the first time where designers and engineers make the product models available, this stage promises a lot of opportunities for sustainability. The tools used for designing and modeling are quite successful in providing the correct information about the material usage. LCA tools, at the same time, are available to use this information for improving the environmental sustainability - related to calculations such as greenhouse gas emission and other impact categories. Moreover, simulation tools are available to predict the effect on the automobile's gas consumption. This aspect could provide important information about the sustainability of the end product. Prototyping can inform the project manager about the sustainability status in an early stage of the manufacturing. Design limitations can influence the environmental sustainability. One example of a design limitation is the choice of specific materials. In some cases, the raw material could be critical and/or toxic. Critical raw materials combine a high economic importance with a high risk associated with their supply [27]. Another example is social impacts in the form of forced or child labor and so on. Moreover, the design decisions of automobile construction imply a different level of effort in manufacturing. For instance, lightweight materials can lead to additional complexity and impacts during raw material extraction and component manufacturing. In some instances, this might omit the gain of a lighter vehicle that potentially consumes less fuel in the subsequent use life cycle phase [28].

As Orsato and Wells [25] stated, $80 \%$ of the value of the completed automobile is constituted by the suppliers of materials and components. Likewise, the largest and most professional purchasing departments can be found in automotive manufacturers. The design stage has a substantial impact on the purchase, yet there are very few systematic approaches to applying sustainability goals together with cost reduction concerns through the stage. These factors and how they relate to the overall environmental sustainability is very much dependent on the specific case and interoperable toolchains, which consider these sustainability aspects and could give real-time assessment infrastructure solutions for LCSA.

Notably, some tools are playing an important role in the use phase performance of the product but do not have sustainability-related opportunities. One of these toolsets is testing tools. Even though the project could be tested by assuring that the components, modules, or functionalities work in all conditions, the testing activities do not provide much information about the three sustainability dimensions. Still, it is possible to include sustainability aspects in testing activities by evaluating, for instance, test generation technologies and their effect on test engineers' workload.

\section{Stage 3: Realize}

The realization stage includes design, production, and sales activities. At this stage, the development of the product is over, and implementation is ready to start. One milestone in this stage is the agreements on potential suppliers and subcontractors. Now, in this stage, stakeholders are aware of the specifications of the outsourced components. The social sustainability concerns already mentioned, for example, about impact categories of human rights (such as child labor and working conditions) should be part of these agreements, and each supplier or subcontractor should report any concerns and their safety measures. Furthermore, it is expected that these parties would also submit complete data of the components they are delivering. These sustainability metrics - both social and environmental - can be integrated with the product life cycle. The sales department is the main responsible party to ask 
for this information. Integrating sales tools with production and project management tools can visualize the overall sustainability for different departments and stakeholders.

Another important milestone is the scheduling of the production activities, which occurs in this stage. The scheduling also implies that the raw materials and tools are decided upon and ordered. Also, in this stage, the staff for the production is assigned. Software developers, designers, and system, control, mechanical, electronic, and test engineers continuously work together. One can include this scheduling information to the LCSA by, for instance, working hours of each stakeholder and energy consumption of each process for economic and social dimensions of sustainability.

Interoperable toolchains are a vital need in the realization stage of CPS manufacturing. During this stage, the project becomes most visible, hence requiring different stakeholders, departments, and tools to be able to work together. Some existing exceptions occur where a few tools are integrated and work in an interoperable way. This generally happens where one vendor has developed more than one tool that uses the same database or has an integration mechanism already developed between them. However, as noted earlier, there are many tools, which are developed by different vendors and do not have any integration solutions. It is outside the scope of this paper to discuss the integration solutions for more interoperable toolchains. Therefore, we will not go in deeper about the specifications of each tool and how each should be integrated. It might be difficult to integrate the sustainability perspective with marketing strategies, but it is possible to include cost analysis for economic dimension and labor-related concerns for the social dimension of sustainability. Accordingly, sales and services affect the sustainability of the product. One example is the transportation of the end product, the vehicle, to the sales offices all around the world. Sales tools should be integrated with the earlier tools, and the final manufacturing sustainability metric can be calculated at this point.

\section{Stage 4: Service}

The last stage in our product life cycle only includes customer support. Customer service is an important stage where one can collect more data about the sustainability of the parts, how often problems occur, and on what parts of the end product. This information can be fed back to the sustainability assessment metrics and ensures the correctness of the assessment techniques. The maintenance cost of the vehicle can be considered as an economic sustainability metric and should include insurance, taxes, cost and water usage of washing, financial services, and parts and service cost.

Software tools and car diagnostic tools in service centers are compatible with each other. It is possible to use this data to assess the sustainability of the end product and to understand how the design, material selection, and so on affect the sustainability of the vehicle in the use phase.

\section{Discussion}

Today, sustainability of a manufacturing process is either not considered at all or done as a separate action, completely isolated from the rest of the stakeholders (engineers, designers, sales and marketing staff, etc.). The approach we are suggesting will increase the awareness of all stakeholders, which will hopefully affect their decisions about material selection, work efficiency, energy consumption, design requirements, and so on. As a result, we can accomplish more sustainable manufacturing processes throughout the product life cycle stage. In this section, we will conceptualize the idea introduced in an earlier section and discuss the architecture of a proposed toolchain.

Fig. 1 illustrates the stage, actions taken by tools, and the three dimensions of sustainability in relation to them for the purpose of answering RQ1. As summarized in Fig. 1, one can use the following important metrics to assess sustainability:

- Social: Workload, working hours, safety, health, work conditions, child labor, forced labor, discrimination, impacts surrounding conflict minerals, local communities, noise impact.

- Economic: Material cost, wages, energy cost, end-oflife cost, production cost, acquisition cost, operation cost, maintenance cost.

- Environmental: Energy consumption, material extraction, material choice, greenhouse gas emissions, toxicity, water consumption, land use, recyclable materials.

Fig. 2 illustrates the stages, set of tools that could be part of each and some example metrics, which can be transferred to assess the sustainability of the manufacturing process. These metrics can be initiated by one tool and throughout the product life cycle stage; other tools can update these metrics. To answer RQ2, we will exemplify the use case and some relevant metrics throughout the product life cycle stages. For instance, a requirements manager can give a workload metric at the beginning, when the first approximation can be done about how much time each requirement will take and how much workload each department will have. Later, during other stages, another tool can revise this first prediction with more specified projections, and during the realization stage, each stakeholder's effort automatically updates this projection in real time. At the end of the manufacturing process, then, it would be possible to have a final metric about a workload. This metric can help, for instance, project management to better understand the processes, and next time they can plan the project more efficiently and more realistically. Moreover, the project manager will be able to see the evolution of the workload metric in real time and can interrupt on time before it further affects the work environment. One can decide to compensate workers correctly according to this workload, can consider increasing the number of team members to decrease this load, can analyze how frequently team members are having a high workload, understand whether any special patterns affect the social sustainability of the workplace, and so on. 


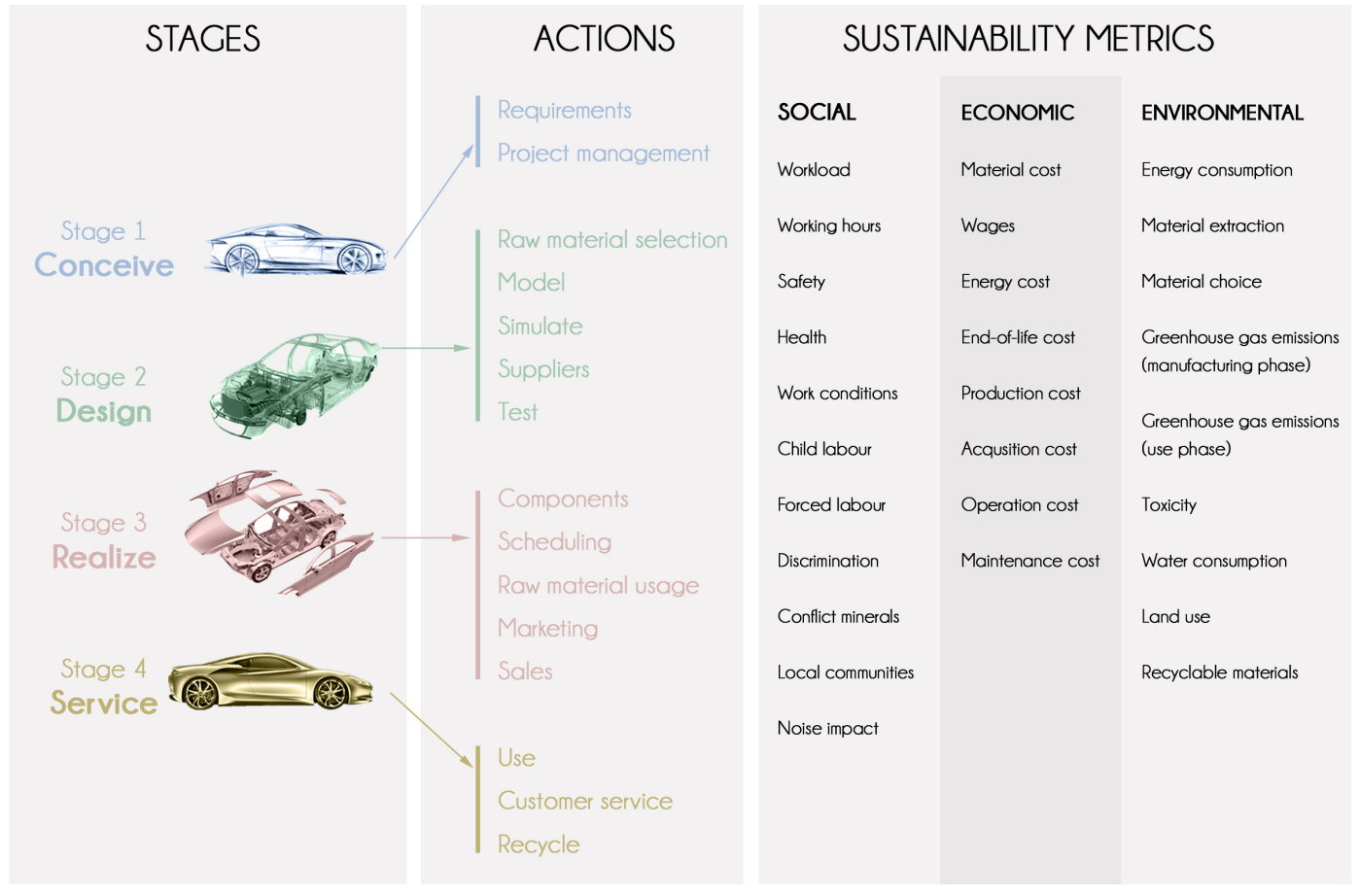

Figure 1. Product life cycle stages, actions connected to each stage, and relevant sustainability metrics for consideration.

Surely, many social issues on which a performance measurement takes place are not easy to quantify. Moreover, this would require extensive research on a real case study with real data. However, in our use case, we mention this dimension and want to underline the importance of it by showing how easily it can be integrated with the interoperable toolchains. Our goal here is not to quantify the social sustainability dimension but to exemplify a method to integrate aspects of social sustainability throughout the product life cycle. For instance, an automobile is an example of a CPS and has several social effects on a society as an end product. Some of these effects are traffic congestion, traffic accidents, and air pollution [29]. We are trying to answer the question of how one can assess the social impact of a CPS - in our case, the impact of an automobile - on society through the product life cycle stages by integrating the sustainability perspective into interoperable toolchains. While one level of the social sustainability dimension concerns the end product itself during the use phase of the product, another level is more focused on the social sustainability of the manufacturing processes of the CPS. For this level, one can try to address needs specific to social issues, such as forced labor, working hours or existence of trade unions, child labor, and so on.

Another example metric that we will talk about is from the economic dimension of sustainability, production cost. At the beginning of the project, one can have a preliminary cost prediction from, for instance, earlier similar projects. Even though the product will be a different automobile, most of the parts/components would be similar or even the same as earlier products. However, our approach makes it possible to have even more accurate predictions. For instance, the material cost is a changing metric. This information can be obtained from tools from the sales department and then fed back to the relevant tools, such as a project management tool where the manager can instantly see the cost change. It is also possible to integrate this information with design tools. This will inform the designer about the cost difference related to material selection. The same example gives a lot of information about the environmental impact of the materials. The stakeholders can see the positive and negative effects of their decisions on environmental, economic, and social dimensions of sustainability, and develop awareness toward more sustainable manufacturing.

Most importantly, this approach can lead to sustainability analysis not only in one dimension, but also benefit understanding and additional merging or comparing of the different dimensions of sustainability. One encounters a chain of complex decision-making mechanisms during the production of a product, and how one decision can affect the next is rarely known, nor is it known whether the result will lead to a more or less sustainable product without the overview of these metrics and their evolution during the manufacturing.

The sustainability assessment approach through interoperable toolchains gives an opportunity to see these decisions in different phases of the life cycle. Moreover, one can use the data about the evolution of these metrics to make analytical observations for improving the sustainability of the manufacturing processes and the sustainability of the end product.

One such approach is to use data visualization and visual analytics to illustrate sustainability metrics, their interrelationships with each other, and an overall sustainability situation. Through visualizations, it is possible to have the ability to promptly gain insights about the current sustainability 


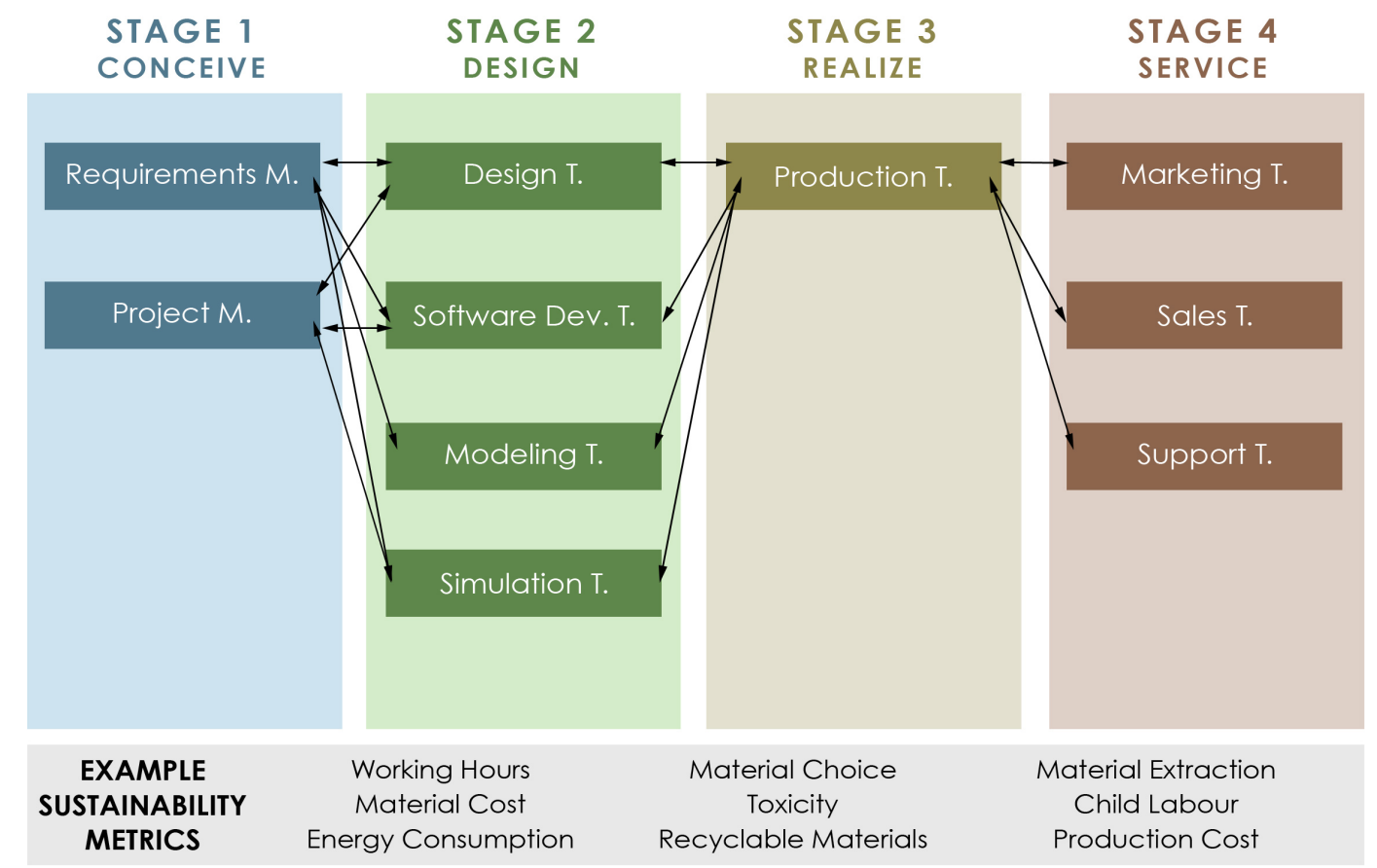

Figure 2. Product life cycle stages, tools, and some example sustainability metrics that can be transferred to assess sustainability.

status of the manufacturing processes. Moreover, it is possible to extract patterns concerning relevant issues, and visual analytics allows iterative work with these patterns [30]. With this approach, one can select relevant metrics for each stakeholder and develop dashboards that can show these metrics in real time, hence informing stakeholders about the current sustainability situation and how their decisions are influencing each dimension. This can be also automated with visual analytics and generate warnings concerning effective decisions and inform stakeholders to reconsider their preferences. The data visualization and visual analytics approach can also be integrated with the end product and can inform car owners about the sustainability metrics of their vehicles.

The impact of the use phase of an automobile, on sustainability, differs based on the type of vehicle and energy source, the scenario, driver behavior etc. For instance, electrical cars might have generally less environmental impact during use phase when they are compared with standard internal combustion engine vehicles [28]. During the use phase of the automobile, the operation includes the fuel cost, which has a huge effect on economic sustainability. Even though it is impossible to embed this functionality into all cars today, in the future, cars will have constant real-time data flow, which will list the status of the car. The information about fuel usage is one example metric to assess the economic and environmental sustainability of a particular car according to the engine type and usage pattern. Other metrics that one could use for the social dimension of sustainability during the use phase of the automobile are vehicle users and pedestrian safety, the social impact of sound (sound pressure level from engines, exhaust, and rolling noise), number of seats and luggage, and the possibility to travel for the elderly, and disabled [31]. A vehicle use phase impact is closely dependent on the behavior of the user. In this case, it would be possible to use, for example, average data to assess sustainability.

The limitation to the system boundary of this paper is set by available software and metrics for each dimension in every life cycle phase. Although the tools above include all life cycle phases, from raw material extraction to disposal, the actual metrics are lacking for raw material extraction, use, and disposal. This means the metrics for impacts are, at best, theoretical assumptions. The complex chain with several subsuppliers of raw material provides questionable data. Can the buyer at a company find relevant data about material impacts upstream?

During the time of this study, we could not find any software tool used for end-of-life disposal of cars. However, it is possible to implement solutions to extract useful information from earlier life cycle phases to support the recycling of the product. In an interoperable toolchain, all information about valuable raw materials from the earlier stages until this last stage can be listed, and this approach would help the recycling process. Recycling has an impact on all dimensions of sustainability since the extraction of raw materials has an effect socially, environmentally, and includes enormous costs during the process. During disposal, there is no detailed follow-up for recycled amounts from the end-of-life vehicles. Therefore, no relevant data can be assessed. 


\section{CONCLUSION}

Today's challenges in CPS manufacturing require interoperable design and development toolchains. The stages of these toolchains are still in development and the focus of many research initiatives. This research underlines the importance of including sustainability-related metrics to interoperable toolchains without necessarily concentrating on the technical discussion about interoperability solutions.

The proposed research identifies the important metrics from social (workload, working hours, safety, health, work conditions, child labor, forced labor, discrimination, impacts surrounding conflict minerals, local communities, noise impact), economic (material cost, wages, energy cost, end-oflife cost, production cost, acquisition cost, operation cost, maintenance cost), and environmental (energy consumption, material extraction, material choice, greenhouse gas emissions, toxicity, water consumption, land use, recyclable materials) dimensions of sustainability.

Moreover, this paper exemplifies how these metrics can possibly flow through different software tools for the purpose of assessing sustainability. The use case practice illustrated how one can identify sustainability metrics and request integration solutions to include these metrics for better sustainability.

While the need for faster, better-integrated toolchains constitutes the push toward researchers and the industry to develop appropriate integration solutions, sustainability-related research in this research field is still missing. This study offers evidence of the concept's merits and encourages interoperability researchers to develop solutions by taking sustainability into consideration.

\section{REFERENCES}

[1] E. A. Lee and S. A. Seshia, Introduction to Embedded Systems - A cyber-Physical Approach, $1^{\text {st }}$ ed. 2011.

[2] IEEE, "IEEE standard computer dictionary: A compilation of IEEE standard computer glossaries." New York, NY, 1990.

[3] Teknikföretagen, "Made in Sweden 2030: Strategic agenda for innovation in production (in Swedish)." Stockholm, 2013.

[4] G. H. Brundtland, "Report of the World Commission on Environment and Development: Our Common Future," Oslo, 1987.

[5] M. van Marrewijk, "Concepts and definitions of CSR and corporate sustainability: Between agency and communion," J. Bus. Ethics, vol. 44, no. 2, pp. 95-105, 2003.

[6] H. Kagermann, W. D. Lukas, and W. Wahlster, "Industrie 4.0: Mit dem Internet der Dinge auf dem Weg zur 4. industriellen Revolution.," VDI nachrichten, Berlin, Apr. -2011.

[7] acatach, "Umsetzungsempfehlungen für das Zukunftsprojekt Industrie 4.0 - Abschlussbericht des Arbeitskreises Industrie 4.0,” 2013.

[8] T. Stock and G. Seliger, "Opportunities of Sustainable Manufacturing in Industry 4.0," Procedia CIRP, vol. 40, no. Icc, pp. 536-541, 2016.

[9] S. Schaltegger and M. Wagner, "Sustainable entrepreneurship and sustainability innovation: Categories and interactions," Bus. Strateg. Environ., vol. 20, no. 4, pp. 222-237, 2011.

[10] N. M. P. Bocken, S. W. Short, P. Rana, and S. Evans, "A literature and practice review to develop sustainable business model archetypes," $J$. Clean. Prod., vol. 65, pp. 42-56, 2014.

[11] M. Swat, H. Brünnet, and D. Bähre, "Selecting manufacturing process chainsManufacturing Process Chains in the early stageEarly Stage of the product engineering processProduct Engineering Process with focusFocus on energy consumptionEnergy Consumption," Technol. Manuf. Process Sel.,pp. 153-173, 2014.

[12] ISO, "ISO 16100-1:2009 Industrial automation systems and integrationManufacturing software capability profiling for interoperability - Part 1: Framework." 2009.
[13] B. Penzenstadler, V. Bauer, C. Calero, and X. Franch, "Sustainability in software engineering: A systematic literature review," in 16th International Conference on Evaluation \& Assessment in Software Engineering (EASE 2012), 2012, pp. 32-41.

[14] M. Dassisti, R. Jardim-Goncalves, A. Molina, O. Noran, H. Panetto, and M. M. Zdravković, "Sustainability and interoperability: Two facets of the same gold medal," in Lecture Notes in Computer Science (EI2N'2013), 2013, vol. 8186 LNCS, pp. 250-261, 2013.

[15] C. Agostinho, Y. Ducq, G. Zacharewicz, J. Sarraipa, F. Lampathaki, R. Poler, and R. Jardim-Goncalves, "Towards a sustainable interoperability in networked enterprise information systems: Trends of knowledge and model-driven technology," Comput. Ind., vol. 79, pp. 64-76, 2016.

[16] R. Jardim-Goncalves, K. Popplewell, and A. Grilo, "Sustainable interoperability: The future of Internet based industrial enterprises," Comput. Ind., vol. 63, no. 8, pp. 731-738, 2012.

[17] ISO, "ISO 14040:2006. Environmental Management: Life Cycle Assessment, Principles and Framework." International Organization for Standardization, Geneva, 2006.

[18] United Nations Environmental Program (UNEP), Towards a Life Cycle Sustainability A ssessment: Making Informed Choicesinformed choices on Productsproducts. 2011.

[19] M. Finkbeiner, E. M. Schau, A. Lehmann, and M. Traverso, "Towards life cycle sustainability assessment," Sustainability, vol. 2, no. 10, pp. 3309-3322, 2010.

[20] S. Poulikidou, "A literature review on methods and tools for environmentally friendly product design and development," Stockholm, 2012

[21] J. Woodhouse, Managing Industrial Risk: Getting Value for Money in Your Business. Chapman \& Hall, 1993.

[22] A. C. Márquez, C. P. Márquez, J. F. G. Fernández, M. L. Campos, and V. G.-P. Díaz, "Asset Management," in Asset Management, T. Van der Lei, P. Herder, and Y. Wijnia, Eds. Dordrecht: Springer Netherlands, 2012.

[23] UNEP Setac Life Cycle Initiative, Guidelines for Social Life Cycle Assessment of Products, vol. 15, no. 2. 2009.

[24] GRI, "Sustainability reporting guidelinesReporting Guidelines," pp. 1104, 2002.

[25] R. J. Orsato and P. Wells, "The Automobile Industry \& Sustainability," J. Clean. Prod., vol. 15, no. 11-12, pp. 989-993, Jan. 2007.

[26] G. Wijnen and P. Storm, Projectmatig Werkenwerken. Spectrum, 2007.

[27] European Commission, "Communication from the Commission: On the review of the list of critical raw materials for the $\mathrm{EU}$ and the implementation of the Raw Materials Initiative," Brussels, 2014.

[28] K. T. Gradin, "The Importance of System Boundaries for Environmental Assessment of Vehicles," KTH, 2016.

[29] S. H. Noh, "Equity Implications of Subway Use in Seoul, Korea.," $J$. Korea Geogr. Soc., vol. 30, no. 4, pp. 352-363, 1995.

[30] D. Gürdür, J. El-Khoury, T. Seceleanu, and L. Lednicki, "Making Interoperability Visible: Data Visualization of Cyber-physical Systems Development Tool Chains," J. Ind. Inf. Integr., vol. 4, pp. 26-34, 2016.

[31] W.-P. Schmidt and A. Taylor, "Ford of Europe's Product Sustainability Index," 13th CIRP Int. Conf. LIFE CYCLE Eng., pp. 5-10, 2006. 